\title{
Adenosine inhibits migration, invasion and induces apoptosis of human cervical cancer cells
}

\author{
Z. W. GAO ${ }^{\ddagger}$, H. P. WANG ${ }^{\ddagger}$ K. DONG, F. LIN, X. WANG, H. Z. ZHANG* \\ Department of Clinical Diagnosis, Tangdu Hospital, Fourth Military Medical University, Xinsi Road, Xian, Shanxi 710038, China \\ ${ }^{*}$ Correspondence: Dr_HZZhang@126.com \\ Contributed equally to this work.
}

Received July 23, 2015 / Accepted September 9, 2015

\begin{abstract}
Extracellular adenosine is a key signaling molecule which mediates immune suppression, angiogenesis, and regulates cancer cells growth. The effect of adenosine on cervical cancer cells migration and invasion has not been well studied. In the current study, we used Hela and $\mathrm{SiHa}$ cell lines to evaluate the effects of adenosine on cervical cancer cells migration, invasion, and apoptosis. The results showed that adenosine treatment inhibited the migration and invasion activities of Hela and SiHa cells. Moreover, by determining the expression of molecules which were involved in epithelial to mesenchymal transition (EMT) progress, we found that epithelial marker E-cadherin was significantly increased in response to adenosine treatment, while the mesenchymal markers including $\mathrm{N}$-cadherin and fibronectin were decreased. These data suggested that adenosine inhibited cervical cancer cells via repressing the EMT progress. The flow cytometry analysis showed that adenosine could also induce cervical cancer cell apoptosis, which mechanism was further confirmed by investigating the expression levels of apoptosis related molecules, via activating mitochondrial apoptosis pathway. These data might suggest that adenosine could be used as an agent for the treatment of cervical cancer.
\end{abstract}

Key words: adenosine, cervical cancer, migration, invasion, apoptosis

Cervical cancer, a cancer arising from cervix is due to the abnormal proliferation of cells that have the ability to evade growth suppression. Cervical cancer is high in the rank of cancers affect women, with both the fourth-highest incidence and the fourth-highest fatality rate among women worldwide [1]. Infection with specific types of human papilloma virus (HPV) has been found to be involved in the development of most of cervical cancer cases [2]. Other factors, such as smoking, a weak immune system, numbers of sexual partners and hormonal contraceptive, also seem to be involved in the cervical cancer progression $[3,4]$. These risk factors can lead to the alterations of proliferation and invasion of epithelial cells, and finally, trigger cervical cancer development and metastasis. Thus, the effective treatment for cervical cancer will require agents to suppress the proliferation and invasion of cervical cancer cells.

Adenosine is a metabolite from ATP degradation which is catalyzed by ectonucleotidase cascade [5]. As an important purine signaling molecule in tumor microenvironment, adenosine has been found to be involved in cancer growth and progression [6,7]. Firstly, accumulating data have shown that adenosine can mediate immune suppression in vivo [8]. High levels of adenosine in tumor microenvironment could inhibit immune response through multiple pathways, which include block of the NK cells lytic activity $[9,10]$, deregulation of mononuclear phagocyte cell differentiation and maturation [11], and suppression of effector T cells [12]. In addition to the immune suppression effect, several evidences have supported that adenosine can also stimulate tumor angiogenesis via increasing vascular endothelial growth factor production $[13,14]$. Apart from immune suppression and pro-angiogenic action roles of adenosine, recently, researchers investigated the direct effect of extracellular adenosine on cancer cells proliferation in vitro by adding adenosine into culture medium [8, 15-19], and interestingly, opposing effects of adenosine on different cancer cell lines were found (i.e., inhibited cells proliferation in some cell lines and promoted in others) [16, $17,19]$.

The effect of extracellular adenosine on human cervical cancer cells migration and invasion has not been well studied. 
In the present study, we investigated the effect of extracellular adenosine on migration and invasion of Hela and $\mathrm{SiHa}$ cell lines. Our results revealed that adenosine could also diminish cervical cancer cells migration and invasion through repressing the EMT progress. Moreover, adenosine also induces apoptosis via the mitochondrial apoptosis pathway.

\section{Materials and methods}

Cell culture. Two human cervical cancer cell lines, Hela and SiHa (American Type Culture Collection, ATCC), were used in this study. The cells were grown adherently in DMEM medium (Gibco, Carlsbad, NY, USA) supplemented with 10\% heat-inactivated Fetal bovine serum (FBS, Sijiqing Biotec, Hangzhou, China) in a humidified incubator with $5 \% \mathrm{CO}_{2}$ at $37^{\circ} \mathrm{C}$.

Migration assays. The effect of extracellular adenosine on Migration of Hela and SiHa cells was examined by scratch assay. Cells were cultured in six - well plate with complete medium (DMEM plus 10\% FBS). The scratch was performed with a pipette tip when cell density reached to $80 \%$. Once scratch was made, cells were gently washed by PBS twice, following cultured with serum-free medium containing different concentration of adenosine $(0,10 \mu \mathrm{M}, 100 \mu \mathrm{M}, 1 \mathrm{mM})$. Images were captured immediately and $24 \mathrm{~h}$ after the scratch was made. The cell migration distance was measured by HMIAS - 2000 software. The migration ability of cells was mirrored by relative migration ratio: Relative migration ratio $=($ Start distant - End distance) / Start distance.

Invasion assay. Invasion assay was performed in transwell chamber. Cells were seeded in matrigel coated filters $\left(5 \times 10^{4}\right.$ cells / fliter) and cultured with $200 \mu \mathrm{l}$ serum-free medium (0, $10 \mu \mathrm{M}, 100 \mu \mathrm{M}, 1 \mathrm{mM}$ adenosien plus). $500 \mu \mathrm{l}$ completed medium was added to lower compartments of the chambers. After $24 \mathrm{~h}$ incubation in the $5 \% \mathrm{CO}_{2}$ incubator at $37^{\circ} \mathrm{C}$, the cells on the upper surface of the filter was wiped off using a swab, while cells that invaded through the filter were fixed, stained with crystal violet and counted.
Cell apoptosis analysis. Cell apoptosis was detected using the annexin V-FITC apoptosis detection kit (KeyGEN BioTECH, Nanjing, China). Briefly, Hela and SiHa cells treated with $500 \mu \mathrm{M}$ adenosine for $48 \mathrm{~h}$ were collected and washed with PBS twice, stained for $15 \mathrm{~min}$ in the dark at room temperature with annexin V-FITC and propidium iodide (PI), and the cells treated with PBS was also stained as negative control. Following that, cell apoptosis was examined using FACS calibur flow cytometer (BD Biosciences, San Jose, USA). The percentage of apoptotic cells was calculated with WinMDI software. The cell apoptosis = early apoptosis (Quadrant 4) plus late apoptosis (Quadrant 1).

Quantitative real-time RT-PCR. Total RNA was isolated from cells using Trizol reagent, then $1 \mu \mathrm{g}$ of RNA were used for cDNA synthesis by using Primescript RT Master (Takara, Dalian, China). RT-PCR was carried out using the SYBR Green kit (Invitrogen, Carlsbad, USA) according to the manufacturer's instructions. The relative expression levels of genes were normalized to the endogenous housekeeping gene $\beta$-actin. The primers sequences are listed in Table 1.

Western-blot analysis. Cells were harvested in lysis buffer (20 mM Tris-Hcl, 0.5\% NP-40, $0.5 \mathrm{mM}$ PMSF). The protein concentration was determined by BAC protein quantify kit (Dingguo Biotech, Beijing, China). $50 \mu \mathrm{g}$ of protein sample was loaded for SDS-PAGE, and then transferred onto PVDF membranes. Membranes were incubated in blocking buffer (5\% non - fat dried milk in PBST (PBS containing 0.1\% tween-20)) for $2 \mathrm{~h}$ at room temperature, and then incubated with primary antibody overnight at $4{ }^{\circ} \mathrm{C}$. After washed with PBST for three times (each for $15 \mathrm{~min}$ ), membranes were incubated with secondary antibody for $2 \mathrm{~h}$ at room temperature. After washed with PBST, proteins were detected with western blotting luminol reagent (Santa Cruz Biotechnology, Santa Cruz, USA), $\beta$-actin expression were used as the internal standard.

Statistical analysis. The data are expressed as the mean \pm standard deviation. Statistical evaluation of the data was performed by one-way analysis of variance. Data comparisons

Table 1. Primer sequence used in RT-PCR analysis

\begin{tabular}{lll}
\hline Target gene & Forward primer $(5-3)$ & Reverse primer $\left(5^{\prime}-3^{\prime}\right)$ \\
\hline Bax & GGGTGGTGGGTGAGACTC & AGACACGTAAGGAAAACGCATTA \\
Bak & ATGGCTTCGGGGCAAGGC & TCATGATTTGAAGAATCTTCGTACC \\
Bcl-2 & GAACTGGGGGAGGATTGTGG & CCGGTTCAGGTAC TCAGTCA \\
Mcl-1 & TGCCGCTGCTGGAGTTGGT & TTACAGTAAGGCTATCTTATTAGAT \\
Caspase-3 & ATGGAAGCGAATCAATGGACTC & CTGTACCAGACCGAGATGTCA \\
E-cadherin & TGCCCAGAAAATGAAAAAGG & GTGTATGTGGCAATGCGTTC \\
N-cadherin & ATGACAATCCTCCAGAGTTTA & ATCCTTATCGGTCACAGTTAG \\
FN1 & CGAGAGTAAACCTGAAGCTG & CCTTCATGGCAGCGGTTTGC \\
Snail & GCCTAGCGAGTGGTTCTTCT & TAGGGCTGCTGGAAGGTAAA \\
MMP-2 & GCCCCAGACAGGTGATCTTG & GCTTGCGAGGGAAGAAGTTGT \\
MMP-9 & TGGCAGAGATGCGTGGAGA & GGCAAGTCTTCCGAGTAGTTTT \\
$\beta$-actin & GACTTAGTTGCGTTACACCTTTC & GACTTAGTTGCGTTACACCTTTC \\
\hline
\end{tabular}


were conducted by using the Student's t-test. $P<0.05$ was considered to be statistically significant.

\section{Results}

Adenosine inhibits migration and invasion of cervical cancer cells. In the current study, we investigated the role of extracellular adenosine on cervical cancer cells migration and invasion, which are the two prerequisite of aggressive behaviour of cancer cells. As shown in Figure 1A, B, treatment with extracellular adenosine significantly diminished migration ability of Hela and SiHa cells. After treatment with $100 \mu \mathrm{M}$ of adenosine for $24 \mathrm{~h}$, the distance of adenosine treated Hela and SiHa cells migration was decreased by $20 \%$ and $24 \%$, while $1 \mathrm{mM}$ of adenosine diminished Hela and SiHa cells migration by $32 \%$ and $33 \%$ (Fig. 1B). Moreover, extracellular adenosine also suppressed cervical cancer cells invasion. As shown in Figure 1C, compared with control cells, treatment with 100 $\mu \mathrm{M}$ of adenosine significantly reduced the number of invaded
Hela and SiHa cells by $21 \%$ and $16 \%$ respectively (Fig. 1C). These finding demonstrated that adenosine could diminish the aggressive behaviour of cervical cancer cells.

MMP-2 and MMP-9 expression were not influenced by adenosine treatment. Given that matrix metalloproteinases (MMPs) usually play important role in tumor invasion and metastasis, we determined the effect of adenosine on MMP-2 and MMP-9 expression in Hela and SiHa cells. However, RT-PCR results showed that expression level of MMP-2 and MMP-9 were not changed in response to adenosine treatment in both Hela and SiHa cells (Fig. 2C). This result demonstrates that adenosine-dependent inhibition of cervical cancer cells migration is not via affect the expression of MMP-2 and MMP-9.

Adenosine treatment decreases mesenchymal markers while increases epithelial markers. The EMT has been well recognized as a crucial step in promoting tumor metastasis. During EMT progress, the characteristic are the loss of epithelial markers such as E-cadherin while increase of mesenchymal
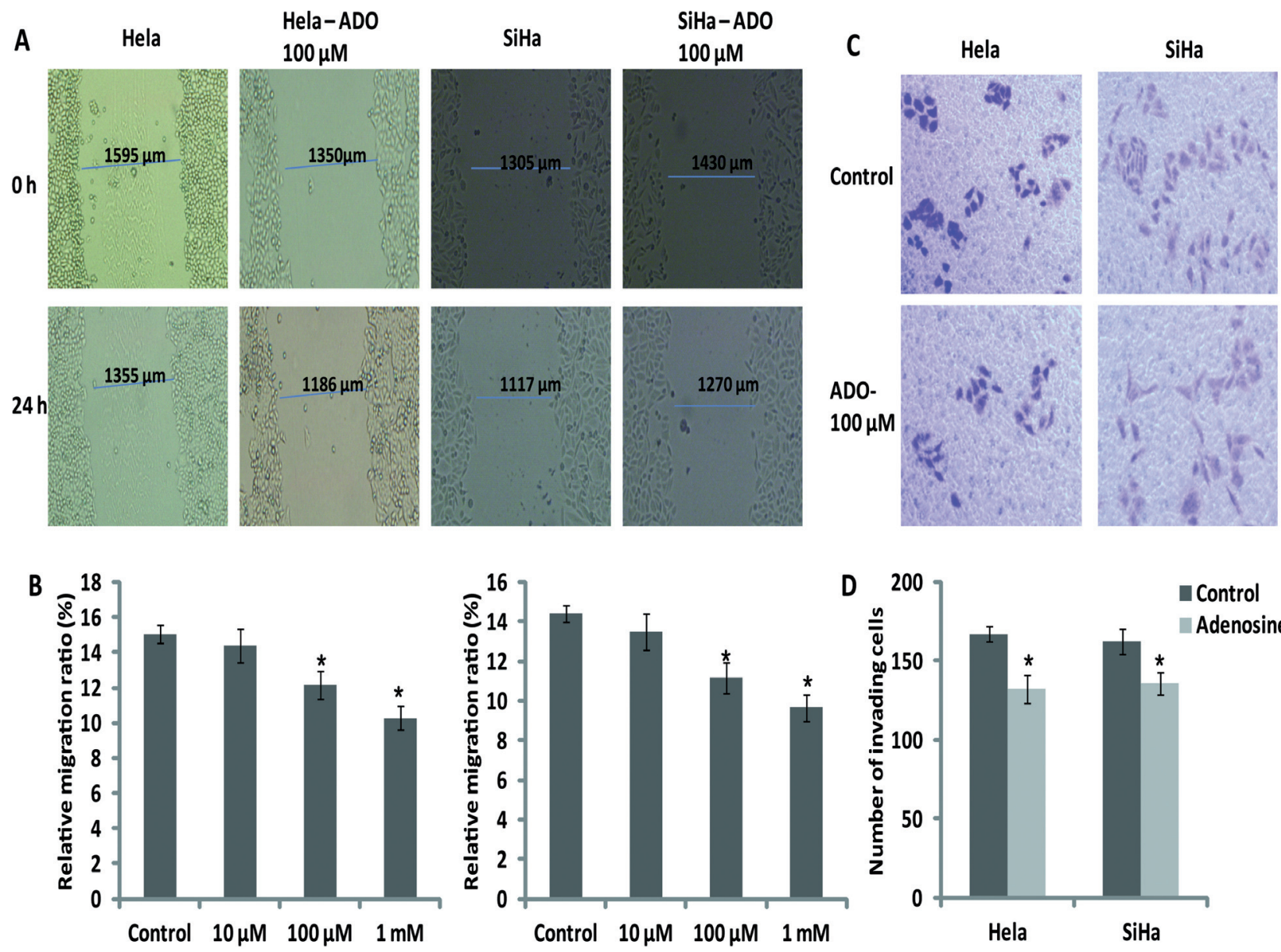

Figure 1. The effect of adenosine on cervical cancer cells migration and invasion. (A, B) Scratch assay was used to observe the effects of adenosine on Hela and SiHa cells migration. The results showed that high concentration of adenosine inhibits cells migration in a dose-dependent manner. 100 $\mu \mathrm{M}$ adenosine inhibits Hela and SiHa cells migration by $19 \%$ and $22 \%$. (C, D) Invasion assay showed that Hela and SiHa cells invasion was suppressed in response to $100 \mu \mathrm{M}$ adenosine treatment. ${ }^{\star} P<0.05$, represent significantly different from the control group. 


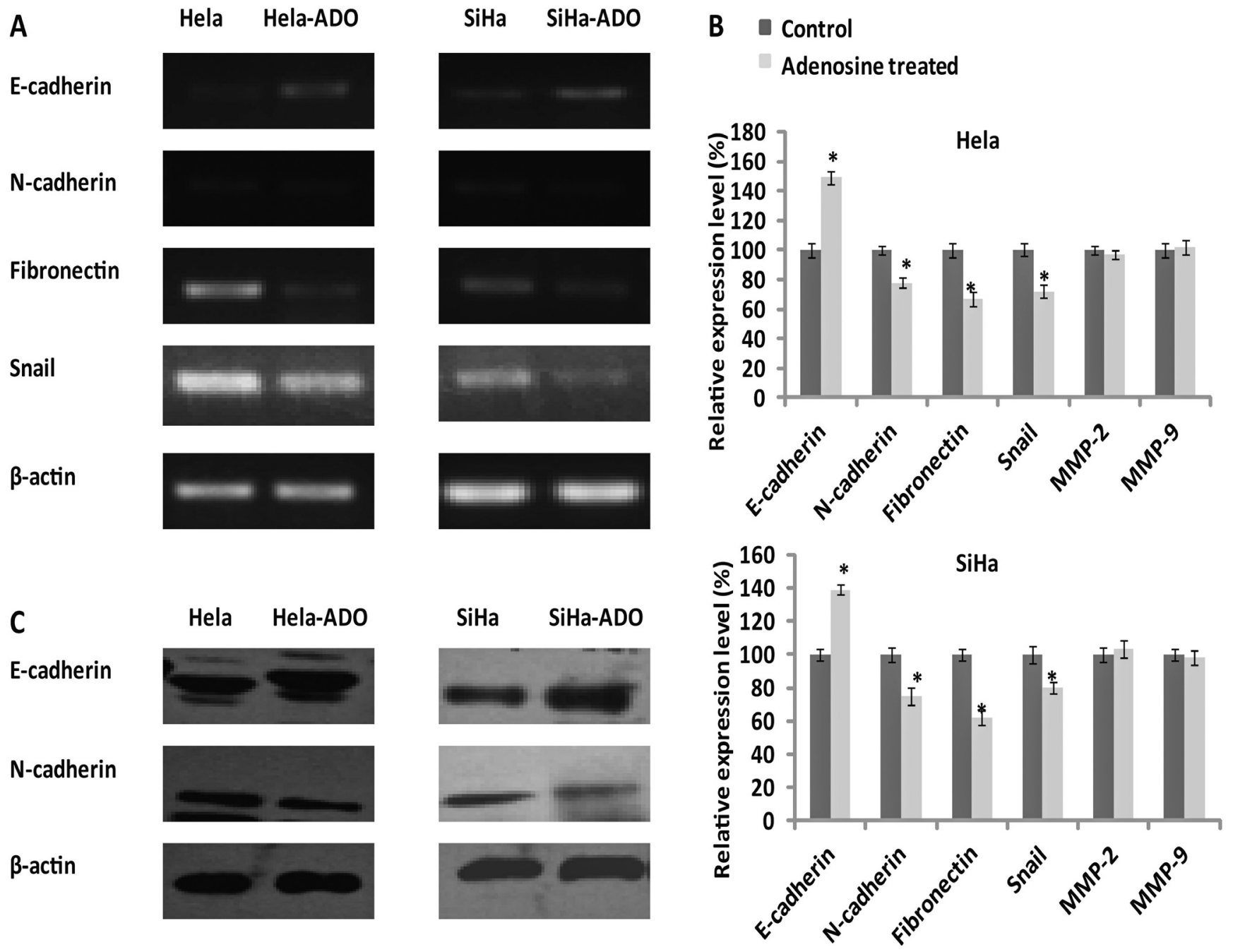

Figure 2. The effect of adenosine on the expression levels of molecules which were involved in cancer cells EMT. (A, B) The expression of relative molecules was examined by using RT-PCR. Compared with in control cells, the expression levels of epithelial marker E-cadherin was significantly increased in adenosine treated cells, while the mesenchymal markers including N-cadherin and fibronectin were decreased. Moreover, the expression of Snail which functions as a transcriptional repressor of E-cadherin is also reduced in adenosine treated cells. (C) Western-blot detected the expression of epithelial marker E-cadherin and mesenchymal marker N-cadherin.

markers such as $\mathrm{N}$-cadherin and fibronectin. In the present study, we investigated the effect of adenosine treatment on EMT markers in Hela and SiHa cells. The RT-PCR and western-blot results showed that the epithelial marker E-cadherin was higher expressed in adenosine treated cervical cancer cells in compared with control cells (Fig. 2B, C). Conversely, the expression of mesenchymal markers fibronectin and $\mathrm{N}$ cadherin were decreased in response to adenosine treatment (Fig. 2B). Moreover, the expression of another key EMT mediator - Snail, which functions as a transcriptional repressor of E-cadherin is also reduced in adenosine treated cells (Fig. 2A, $\mathrm{B}$ ). These results suggested that adenosine inhibited migration of cervical cancer cell via repressing EMT progress.

Adenosine induces apoptosis of cervical cancer cells via mitochondrial apoptotic pathway. We also evaluated the effect of adenosine on cell apoptosis by flow cytometry detection. As shown in Figure 3, The percentage of apoptotic cells of control were only $1.28 \%$ and $1.59 \%$, while total apoptotic cells of adenosine treated Hela and $\mathrm{SiHa}$ cells reached $19.84 \%$ and $18.73 \%$ respectively (Fig. 3 ). And then, in order to understand the mechanisms of cancer cells apoptosis induced by adenosine, the expression levels of pro-apoptotic proteins (Bax and Bak) and antiapoptotic proteins (Bcl-2 and $\mathrm{Mcl}-1$ ) were analyzed. The results showed that adenosine treatment caused significant reduction of Bcl-2 expression by $30 \%$ in both cells, while the expression levels of Bax and Bak were up-regulated by about $52 \%, 63 \%$ and $29 \%, 38 \%$ in Hela and $\mathrm{SiHa}$ cells, respectively (Fig. 4). Moreover, caspase-3 expression was also increased by $83 \%$ and $51 \%$ in adenosine treated Hela 

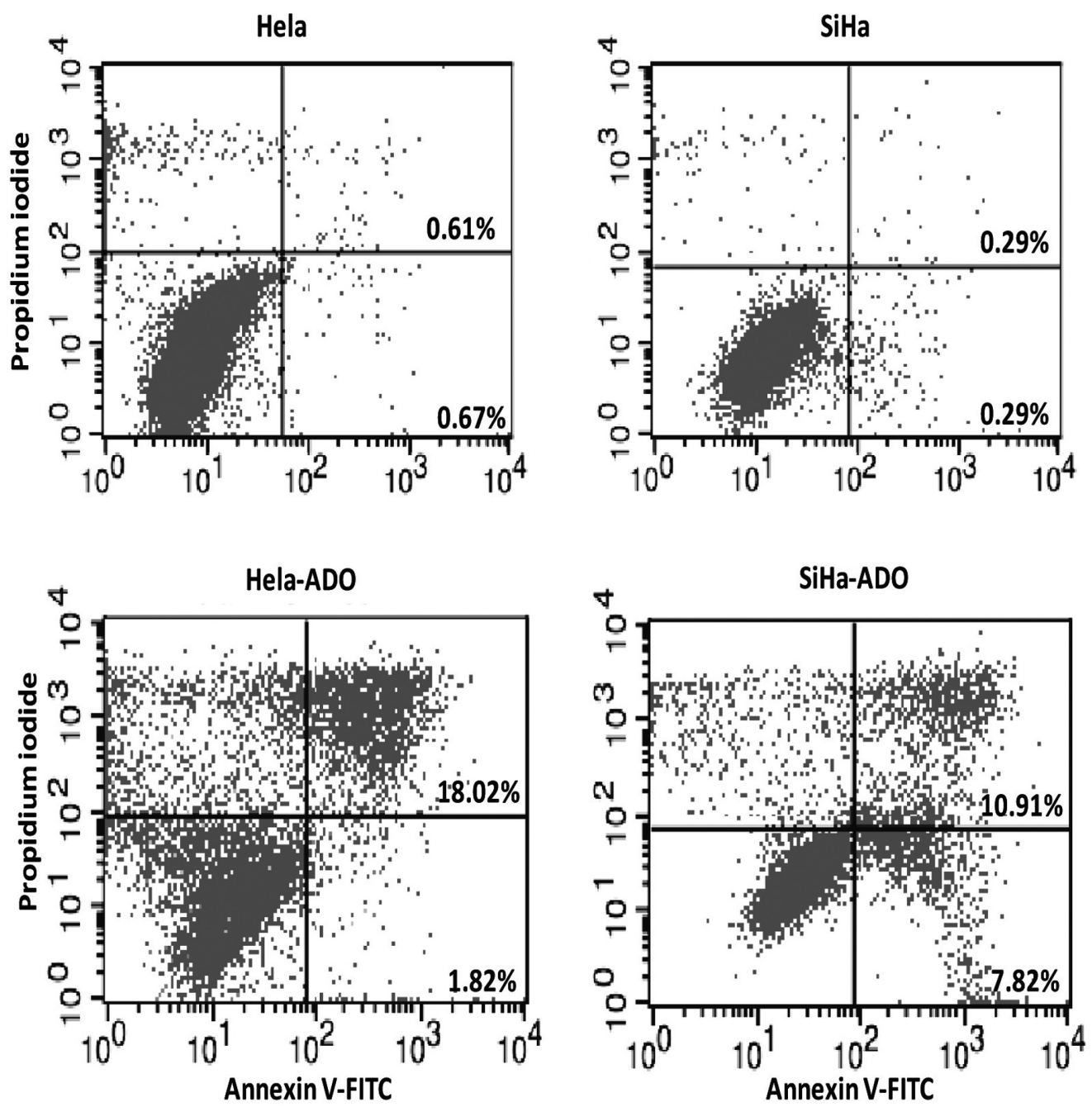

Figure 3. Flow cytometry detection of apoptosis in Hela and SiHa cervical cancer cells treated with adenosine. Hela and SiHa represent the control cells which cultured with normal media, while Hela-ADO and SiHa-ADO represent the cells treated with adenosine for 48h. The percentage of apoptotic cells was calculated with WinMDI software. The early apoptotic cell group were in Quadrant 4 (stained only with annexin V), and late apoptotic cells were in Quadrant 1 (stained with both annexin V and PI).

and SiHa cells compared to control cells (Fig. 4). These findings suggested that extracellular adenosine induced apoptosis of cervical cancer cells via activating mitochondrial apoptosis pathway.

\section{Discussion}

Adenosine signaling has emerged as an important player in cancer progression. The effect of adenosine on cervical cancer cells is not well studied. This study was undertaken to evaluate the effect of adenosine in migration, invasion and apoptosis of $\mathrm{Hela}$ and SiHa cells in vitro. The major findings of the present study are summarized as followings: 1) Extracellular adenosine inhibits the migration and invasion of cervical cancer cells through repressing the EMT progress. 2) Extracellular adenosine induces apoptosis of cervical cancer cells via the mitochondrial apoptosis pathway.

Metastasis is a vicious characteristic of malignance cancers. During cancer metastasis, enhanced motility of cancer cells is the prerequisite. In this study, we found that the extracellular adenosine had migration and invasion inhibition effect in cervical cancer cells. As the epithelial to mesenchymal transition has been recognized an important event which involved in the cancer cell obtaining the invasive phenotype. EMT renders the cancer cells more migratory and invasive capacities. During EMT process, the expression of epithelial markers is reduced while mesenchymal markers are increased. Thus, we determined the effect of adenosine in EMT markers expression in Hela and SiHa cells. In response to adenosine treatment, the expression level of epithelial marker - E-cad- 


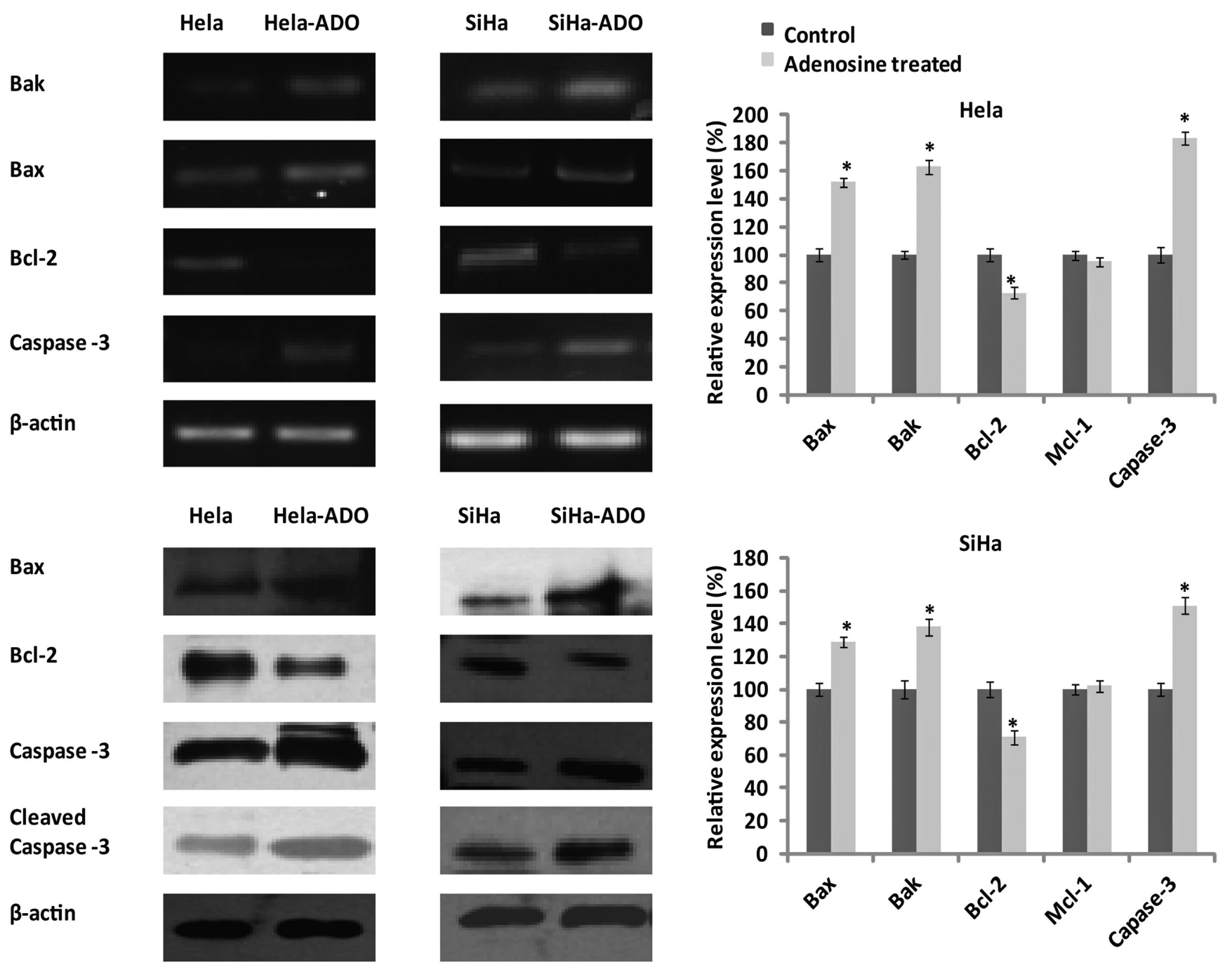

Figure 4. Adenosine treatment activated mitochondrial apoptosis pathway. The expression level of anti-apoptotic protein Bcl-2 were decreased by $30 \%$ in adenosine treated Hela and SiHa cells, while the expression of proapoptoic protein Bax and Bak were increased by $29 \%$ and $38 \%$ respectively. Morover, the pro-apoptotic signaling protein caspase- 3 were increased by $83 \%$ and $51 \%$ in response to adenosine treatment.

herin was significantly increased. E-cadherin is a key protein of cell-cell junction to hold epithelial cells tight together, and acts as a metastatic suppressor. Previous studies have shown that loss of E-cadherin expression is a prerequisite for metastasis of tumor cells [20-22]. Oppositely, the expression of mesenchymal markers (N-cadherin, fibronectin, Snail) was significantly reduced in response to adenosine treatment. Thus, our results demonstrated that adenosine inhibited the migration and invasion of cervical cancer cells through repressing the EMT progress.

Programmed cell apoptosis prevents the uncontrolled proliferation of potentially tumorigenic cell and thus serves as a natural barrier to cancer development $[23,24]$. The apoptotic trigger is controlled by counterbalancing of pro-apoptotic and anti-apoptotic proteins $[25,26]$. In this study, adenos- ine induces apoptosis of Hela and SiHa cells. We found that adenosine up-regulated the pro-apoptotic molecule Bax and Bak while down-regulated the anti-apoptotic molecule Bcl-2, which meant that the balance between pro and anti-apoptotic factors was destroyed, and subsequently, the increased Bax and Bak could disrupte the integrity of the outer mitochondrial membrane, causing the release of a cascade of pro-apoptotic signaling molecule (the most important of which is caspase-3) which played the function via their proteolytic activities to induce the multiple cellular changes, and finally resulted in the apoptosis of cells. Indeed, our result showed that caspase- 3 was significantly increased in Hela and SiHa cells after adenosine treatment. Thus, our finding demonstrated that adenosine induces cervical cells apoptosis via activating the mitochondrial apoptosis pathway. 


\section{References}

[1] STEWART BW, WILD CP. World Cancer Report: IARC Nonserial Publication. 2014.

[2] ROSA MI, MEDEIROS LR, ROSA DD, BOZZETI MC, SILVA FR, et al. Human papillomavirus and cervical neoplasia. Cad Saude Publica. 2009; 25: 953-964.

[3] LUHN P, WALKER J, SCHIFFMAN M, ZUNA RE, DUNN $\mathrm{ST}$, et al. The role of co-factors in the progression from human papillomavirus infection to cervical cancer. Gynecol Oncol. 2013; 128: 265-270. http://dx.doi.org/10.1016/j. ygyno.2012.11.003

[4] GADDUCCI A, BARSOTTI C, COSIO S, DOMENICI L, RICCARDO GENAZZANI A. Smoking habit, immune suppression, oral contraceptive use, and hormone replacement therapy use and cervical carcinogenesis: a review of the literature. Gynecol Endocrinol. 2011; 27: 597-604. http://dx.doi.or g/10.3109/09513590.2011.558953

[5] YEGUTKIN GG. Nucleotide- and nucleoside-converting ectoenzymes: Important modulators of purinergic signalling cascade. Biochim Biophys Acta. 2008; 1783: 673-694. http:// dx.doi.org/10.1016/j.bbamcr.2008.01.024

[6] ANTONIOLI L, HASKO G, FORNAI M, COLUCCI R, BLANDIZZI C. Adenosine pathway and cancer: where do we go from here? Expert Opin Ther Targets. 2014; 18: 973-977. http://dx.doi.org/10.1517/14728222.2014.925883

[7] BURNSTOCK G, DI VIRGILIO F. Purinergic signalling and cancer. Purinergic Signal. 2013; 9: 491-540. http://dx.doi. org/10.1007/s11302-013-9372-5

[8] ANTONIOLI L, BLANDIZZI C, PACHER P, HASKO G. Immunity, inflammation and cancer: a leading role for adenosine. Nat Rev Cancer. 2013; 13: 842-857. http://dx.doi.org/10.1038/ $\underline{\operatorname{nrc} 3613}$

[9] RASKOVALOVA T, LOKSHIN A, HUANG X, JACKSON EK, GORELIK E. Adenosine-mediated inhibition of cytotoxic activity and cytokine production by IL-2/NKp46-activated NK cells: involvement of protein kinase A isozyme I (PKA I). Immunol Res. 2006; 36: 91-99. http://dx.doi.org/10.1385/ $\underline{\text { IR:36:1:91 }}$

[10] LOKSHIN A, RASKOVALOVA T, HUANG X, ZACHARIA LC, JACKSON EK, et al. Adenosine-mediated inhibition of the cytotoxic activity and cytokine production by activated natural killer cells. Cancer Res. 2006; 66: 7758-7765. http:// dx.doi.org/10.1158/0008-5472.CAN-06-0478

[11] HASKO G, PACHER P, REGULATION OF MACROPHAGE FUNCTION BY ADENOSINE. Arterioscler Thromb Vasc Biol. 2012; 32: 865-869. http://dx.doi.org/10.1161/ ATVBAHA.111.226852

[12] CEKIC C, LINDEN J, Adenosine A2A receptors intrinsically regulate $\mathrm{CD} 8+\mathrm{T}$ cells in the tumor microenvironment. Cancer Res 2014; 74: 7239-7249. http://dx.doi.org/10.1158/00085472.CAN-13-3581

[13] ERNENS I, LEONARD F, VAUSORT M, ROLLANDTURNER M, DEVAUX Y, et al. Adenosine up-regulates vascular endothelial growth factor in human macrophages. Biochem Biophys Res Commun. 2010; 392: 351-356. http:// dx.doi.org/10.1016/j.bbrc.2010.01.023
[14] ALLARD B, TURCOTTE M, SPRING K, POMMEY S, ROYAL I, et al. Anti-CD73 therapy impairs tumor angiogenesis. Int J Cancer. 2014; 134: 1466-1473. http://dx.doi.org/10.1002/ ijc. 28456

[15] MA Y, ZHANG J, ZHANG Q, CHEN P, SONG J, et al. Adenosine induces apoptosis in human liver cancer cells through ROS production and mitochondrial dysfunction. Biochem Biophys Res Commun. 2014; 448: 8-14. http://dx.doi.org/10.1016/j. bbrc.2014.04.007

[16] YANG D, SONG J, WU L, MA Y, SONG C, et al. Induction of senescence by adenosine suppressing the growth of lung cancer cells. Biochem Biophys Res Commun. 2013; 440: 62-67. http://dx.doi.org/10.1016/j.bbrc.2013.09.030

[17] SHIRALI S, AGHAEI M, SHABANI M, FATHI M, SOHRABI $\mathrm{M}$, et al. Adenosine induces cell cycle arrest and apoptosis via cyclinD1/Cdk4 and Bcl-2/Bax pathways in human ovarian cancer cell line OVCAR-3. Tumor Biol. 2013; 34: 1085-1095. http://dx.doi.org/10.1007/s13277-013-0650-1

[18] AGHAEI M, KARAMI-TEHRANI F, PANJEHPOUR M, SALAMI S, FALLAHIAN F. Adenosine induces cell-cycle arrest and apoptosis in androgen-dependent and -independent prostate cancer cell lines, LNcap-FGC-10, DU-145, and PC3. Prostate. 2012; 72: 361-375. http://dx.doi.org/10.1002/ pros. 21438

[19] BAVARESCO L, BERNARDI A, BRAGANHOL E, CAPPELLARI AR, et al. The role of ecto-5'-nucleotidase/CD73 in glioma cell line proliferation. Mol Cell Biochem. 2008; 319: 61-68. http://dx.doi.org/10.1007/s11010-008-9877-3

[20] ZHOU Y, MING J, XU Y, ZHANG Y, JIANG J. ERbeta1 inhibits the migration and invasion of breast cancer cells through upregulation of E-cadherin in a Id1-dependent manner. Biochem Biophys Res Commun. 2015; 457: 141-147. http:// dx.doi.org/10.1016/j.bbrc.2014.12.038

[21] MO X, ZHANG F, LIANG H, LIU M, LI H, et al. miR-544a promotes the invasion of lung cancer cells by targeting cadherina 1 in vitro. Onco Targets Ther. 2014; 7: 895-900. http:// dx.doi.org/10.2147/OTT.S61695

[22] WONG AS, GUMBINER BM. Adhesion-independent mechanism for suppression of tumor cell invasion by E-cadherin. J Cell Biol. 2003; 161: 1191-1203. http://dx.doi.org/10.1083/ jcb.200212033

[23] ADAMS JM, CORY S. The Bcl-2 apoptotic switch in cancer development and therapy. Oncogene. 2007; 26: 1324-1337. http://dx.doi.org/10.1038/sj.onc. 1210220

[24] GOLDAR S, KHANIANI MS, DERAKHSHAN SM, BARADARAN B. Molecular Mechanisms of Apoptosis and Roles in Cancer Development and Treatment. Asian Pac J Cancer Prev. 2015; 16: 2129-2144. http://dx.doi.org/10.7314/ APJCP.2015.16.6.2129

[25] BAH N, MAILLET L, RYAN J, DUBREIL S, GAUTIER F, et al. Bcl-xL controls a switch between cell death modes during mitotic arrest. Cell Death Dis. 2014; 5: e1291. http://dx.doi. org/10.1038/cddis.2014.251

[26] ALIBEK K, IRVING S, SAUTBAYEVA Z, KAKPENOVA A, BEKMURZAYEVA A, et al. Disruption of Bcl-2 and Bcl-xL by viral proteins as a possible cause of cancer. Infect Agents Cancer. 2014; 9: 44-56. http://dx.doi.org/10.1186/1750-9378-9-44 